\title{
A method to separate process contributions in impedance spectra by variation of test conditions
}

Jensen, Søren Højgaard; Hauch, Anne; Hendriksen, Peter Vang; Mogensen, Mogens Bjerg; Bonanos, Nikolaos; Jacobsen, Torben

Published in:

Journal of The Electrochemical Society

Link to article, DOI:

10.1149/1.2790791

Publication date:

2007

Document Version

Publisher's PDF, also known as Version of record

Link back to DTU Orbit

Citation (APA):

Jensen, S. H., Hauch, A., Hendriksen, P. V., Mogensen, M. B., Bonanos, N., \& Jacobsen, T. (2007). A method to separate process contributions in impedance spectra by variation of test conditions. Journal of The Electrochemical Society, 154(12), B1325-B1330. https://doi.org/10.1149/1.2790791

\section{General rights}

Copyright and moral rights for the publications made accessible in the public portal are retained by the authors and/or other copyright owners and it is a condition of accessing publications that users recognise and abide by the legal requirements associated with these rights.

- Users may download and print one copy of any publication from the public portal for the purpose of private study or research.

- You may not further distribute the material or use it for any profit-making activity or commercial gain

- You may freely distribute the URL identifying the publication in the public portal 


\title{
A Method to Separate Process Contributions in Impedance Spectra by Variation of Test Conditions
}

\author{
Søren Højgaard Jensen, ${ }^{\mathrm{a}, \mathrm{z}}$ Anne Hauch, ${ }^{\mathrm{a}, \mathrm{b}}$ Peter Vang Hendriksen, ${ }^{\mathrm{a}}$ \\ Mogens Mogensen, ${ }^{\mathrm{a}, *}$ Nikolaos Bonanos, ${ }^{\mathrm{a}}$ and Torben Jacobsen ${ }^{\mathrm{b}, *}$ \\ ${ }^{a}$ Fuel Cells and Solid State Chemistry Department, Ris $\phi$ National Laboratory, and ${ }^{b}$ Department of \\ Chemistry, Technical University of Denmark, DK-2800 Kongens Lyngby, Denmark
}

\begin{abstract}
Many processes contribute to the overall impedance of an electrochemical cell, and these may be difficult to separate in the impedance spectrum. Here, we present an investigation of a solid oxide fuel cell based on differences in impedance spectra due to a change of operating parameters and present the result as the derivative of the impedance with respect to $\ln (f)$. The method is used to separate the anode and cathode contributions and to identify various types of processes. (c) 2007 The Electrochemical Society. [DOI: 10.1149/1.2790791] All rights reserved.
\end{abstract}

Manuscript submitted January 4, 2007; revised manuscript received September 6, 2007. Available electronically October $16,2007$.

Mathematical techniques have been proposed to assist in the problem of identifying electrochemical processes in impedance spectra. Schichlein et al. ${ }^{1}$ have presented a technique using Fourier transformation of experimental impedance spectra in order to determine the distribution function in the time domain. In a series of papers Vladikova, Stoynov, and co-workers ${ }^{2,3}$ use the derivative of the impedance with respect to frequency as a working variable. They resolve the impedance spectra into a series resistance, a polarization resistance, and a polarization capacitance, all of which are frequency dependent. A somewhat similar approach was later presented by Darowicki. ${ }^{4}$

These methods extract information about the contributing processes from a single impedance spectrum. In contrast, we use several spectra to isolate the process contributions prior to the data treatment. This enables us to identify and study the contributing processes separately.

The cathode and anode electrode arcs typically overlap in impedance spectra recorded on solid oxide fuel cells (SOFCs). To overcome this problem, impedance spectroscopy has been applied to both symmetrical cells (cells with two identical electrodes on either side of the electrolyte) and to electrodes in a three-electrode setup. ${ }^{5-10}$ Both experimental arrangements suffer the drawback of differing substantially from commercial cells due to the differences in manufacturing. Not only the interpretation of the spectra but also the performance and stability of the electrodes differ from that of anode-supported SOFCs with a thin $(10 \mu \mathrm{m})$ electrolyte. In this work, an SOFC is investigated and, using the presented method, six electrode processes are resolved in the impedance spectra.

The method is based on the change that occurs in an impedance spectrum when an optional operation parameter such as partial pressure of a reactant, temperature, etc., is changed. An impedance spectrum is recorded just before such a change and another spectrum just after the change. The real part of the spectra is differentiated with respect to $\ln (f)$, where $f$ is the frequency. The difference in this quantity, $\partial Z^{\prime}(f) / \partial \ln (f)$, between the two spectra is named $\Delta \dot{Z}^{\prime}$ and is plotted vs $\log (f)$. The resulting spectrum enables detection of processes affected by the altered operation parameter. The difference in the imaginary part of the two impedance spectra (named $\Delta Z^{\prime \prime}$ ) contains almost the same information. However, plotting $\Delta Z^{\prime \prime}$ vs $\log (f)$ does not provide the same resolution in the frequency domain. This is discussed theoretically in the appendix and confirmed by the presented experiments. In addition, the $\Delta \dot{Z}^{\prime}$ spectrum may provide detailed information about the nature of the involved processes.

\footnotetext{
* Electrochemical Society Active Member

${ }^{\mathrm{z}}$ E-mail: soeren.hoejgaard.jensen@ risoe.dk
}

\section{Experimental}

The tested cell is an anode-supported thin electrolyte SOFC. ${ }^{11,12}$ It has a porous support layer of $\mathrm{Ni}$ and yttria-stabilized zirconia (YSZ) with a thickness of $300 \mu \mathrm{m}$. The hydrogen/steam electrode (thickness $10 \mu \mathrm{m}$ ) is porous and made of $\mathrm{Ni}$ and YSZ. The dense YSZ electrolyte has a thickness of $10 \mu \mathrm{m}$. The air/ $\mathrm{O}_{2}$ electrode is porous and $20 \mu \mathrm{m}$ thick. It is made of strontium-doped lanthanum manganite (LSM) and YSZ.

The cells were tested at ambient pressure in alumina housing between two gas-distributor plates made of $\mathrm{Ni}$ and LSM. Ni and Au foils contacting the Ni and LSM gas distribution layers, respectively, were used for current collection. Further details on the setup are given elsewhere. ${ }^{13}$

The cell was tested at $750^{\circ} \mathrm{C}$ at open-circuit voltage (OCV). The feed gas to the LSM/YSZ electrode was $\mathrm{O}_{2} / \mathrm{N}_{2}$ mixtures at a rate of $20 \mathrm{~L} / \mathrm{h}$ ranging from pure $\mathrm{O}_{2}$ to $25 \mathrm{vol} \% \mathrm{O}_{2}$. The feed gas to the $\mathrm{Ni} / \mathrm{YSZ}$ electrode was $\mathrm{H}_{2} / \mathrm{H}_{2} \mathrm{O}$ mixtures at a rate of $25 \mathrm{~L} / \mathrm{h}$ ranging from $5 \mathrm{vol} \% \mathrm{H}_{2} \mathrm{O}$ and $50 \mathrm{vol} \% \mathrm{H}_{2} \mathrm{O}$.

In one experiment the feed gas to the Ni/YSZ was different; the electrode was fed with a $\mathrm{D}_{2} / \mathrm{D}_{2} \mathrm{O}$ (or $\mathrm{H}_{2} / \mathrm{H}_{2} \mathrm{O}$ ) mixture at a rate of $10 \mathrm{~L} / \mathrm{h}$. The $\mathrm{D}_{2} \mathrm{O}$ (or $\mathrm{H}_{2} \mathrm{O}$ ) concentration was $20 \mathrm{vol} \%$. In this experiment the isotope was exchanged but the humidity and flow rate was kept constant.

A Solartron 1260 was used for the impedance measurements. All spectra were recorded with six measurement points per decade.

\section{Theory}

The performance of electrochemical cells depends on a sequence of processes, such as mass transfer of reactants/products, chargetransfer reactions, electronic and ionic conduction, etc. The overall impedance can be represented as a series of impedance elements describing the individual processes, i.e.

$$
Z(\omega)=\sum_{\mathrm{i}} z_{\mathrm{i}}(\omega)
$$

The individual $z_{\mathrm{i}}$ elements may be parallel circuits themselves, consisting of several processes. However, parallel connections of impedance elements such as $(R C)$ circuits, $(R Q)$ circuits, and Gerischer elements are redundant and no separation into individual elements by means of electrochemical measurement techniques may be possible. Even when $Z$ is known in a large frequency range, it may prove difficult if not impossible to determine the individual $z_{\mathrm{i}}$ elements.

Now suppose an operation parameter, $\Psi$ (flow rate, gas composition, temperature, etc.), is slightly changed from condition A to condition B. As a result, a number of impedance elements, $z_{\mathrm{j}}$, are modified and a number, $z_{\mathrm{k}}$, stays constant. Hence, for this small change in $\Psi$, say $\Delta \Psi=\Psi_{\mathrm{B}}-\Psi_{\mathrm{A}}$, the change in $Z$ can be written as 


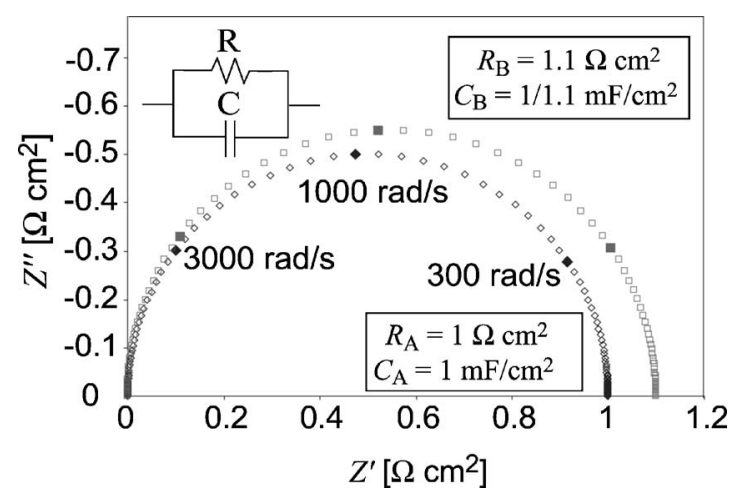

Figure 1. The impedance arcs of an $(R C)$ circuit in condition $\mathrm{A}$ and $\mathrm{B}$. Element values are given in the figure. Angular frequencies are presented for the closed symbols.

$$
\begin{aligned}
\Delta Z= & \left.Z\right|_{\mathrm{B}}-\left.Z\right|_{\mathrm{A}} \cong \frac{\partial Z}{\partial \Psi} \Delta \Psi=\sum_{\mathrm{i}} \frac{\partial z_{\mathrm{i}}}{\partial \Psi} \Delta \Psi=\sum_{\mathrm{j}} \frac{\partial z_{\mathrm{j}}}{\partial \Psi} \Delta \Psi \\
& +\sum_{\mathrm{k}} \frac{\partial z_{\mathrm{k}}}{\partial \Psi} \Delta \Psi=\sum_{\mathrm{j}} \frac{\partial z_{\mathrm{j}}}{\partial \Psi} \Delta \Psi \cong \sum_{\mathrm{j}}\left(\left.z_{\mathrm{j}}\right|_{\mathrm{B}}-\left.z_{\mathrm{j}}\right|_{\mathrm{A}}\right)
\end{aligned}
$$

where are omitted for simplicity. We now define

$$
\dot{Z}(\omega)=\frac{\partial Z(\omega)}{\partial \ln (\omega)} \quad \text { and } \dot{z}_{\mathrm{i}}(\omega)=\frac{\partial z_{\mathrm{i}}(\omega)}{\partial \ln (\omega)}
$$

The change in $\dot{Z}$ can then be written as

$$
\Delta \dot{Z}(\omega)=\left.\frac{\partial Z(\omega)}{\partial \ln (\omega)}\right|_{\mathrm{B}}-\left.\frac{\partial Z(\omega)}{\partial \ln (\omega)}\right|_{\mathrm{A}} \cong \sum_{\mathrm{j}}\left(\left.\dot{z}_{\mathrm{j}}\right|_{\mathrm{B}}-\left.\dot{z}_{\mathrm{j}}\right|_{\mathrm{A}}\right)
$$

Hence, with a careful choice of $\Psi$ it is possible to extract a signal from one or a few elements present in the sum of elements in Eq. 1. This makes it possible to selectively detect elements contributing in the impedance spectrum where the contribution may be hidden in overlapping contributions from other elements.

As an example, let us consider an $(R C)$ circuit. For further analysis, see the Appendix. Figure 1 shows the impedance arc of an $(R C)$ circuit in conditions A and B. The values of the circuit elements for each impedance arc are shown in the figure. Values of $\omega$ are given for the closed symbols.

Because $Z^{\prime}(\omega)$ is only known for a discrete set of frequencies $\left\{\omega_{1}, \omega_{2} \ldots \omega_{N}\right\}$, for the $n$th frequency between 2 and $N-1$, the real part of Eq. 4 can be rewritten as

$$
\Delta \dot{Z}^{\prime}\left(\omega_{n}\right) \cong \frac{\left[Z_{\mathrm{B}}^{\prime}\left(\omega_{n+1}\right)-Z_{\mathrm{B}}^{\prime}\left(\omega_{n-1}\right)\right]-\left[Z_{\mathrm{A}}^{\prime}\left(\omega_{n+1}\right)-Z_{\mathrm{A}}^{\prime}\left(\omega_{n-1}\right)\right]}{\ln \left(\omega_{n+1} / \mathrm{rad} \mathrm{s}^{-1}\right)-\ln \left(\omega_{n-1} / \mathrm{rad} \mathrm{s}^{-1}\right)}
$$

where $Z_{\mathrm{A}}^{\prime}(\omega)$ is the real part of the spectrum in Fig. 1 in condition A at the frequency $\omega$ and $Z_{\mathrm{B}}^{\prime}(\omega)$ is the real part of the other spectrum at $\omega . \Delta \dot{Z}^{\prime}(\omega)$ is plotted vs log frequency in Fig. 2 and labeled " $R_{2}$ inc., $C_{2}$ dec." Such a plot of $\Delta \dot{Z}^{\prime}(\omega)$ vs log frequency is referred to as a $\Delta \dot{Z}^{\prime}$ spectrum. In Fig. 2, some other $\Delta \dot{Z}^{\prime}$ spectra are shown for various increases (all 10\% increase) and decreases (all 9\% decrease) of $R$ and $C$.

Two main types of $\Delta \dot{Z}^{\prime}$ spectra are defined: (i) Time invariant: The size of the impedance arc is changed, but the characteristic frequency $\omega^{o}$ is constant. The $\Delta \dot{Z}$ ' spectra " $R$ inc., $C$ dec." and " $R$ dec., $C$ inc." in Fig. 2 are time invariant because $\omega^{o}=1 / R C$ is constant. (ii) Time variant: $\omega^{o}$ is changed. The size of the arc may be constant or change. Two subtypes are defined. "Capacitive" is change in capacitance $C$ with a constant $R$. The $\Delta \dot{Z}$ ' spectra " $C$

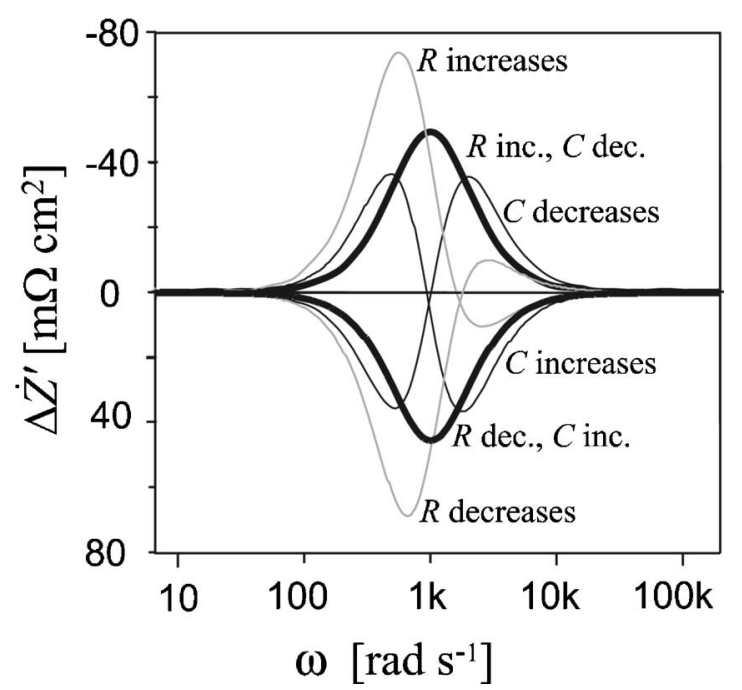

Figure 2. Theoretical $\Delta \dot{Z}^{\prime}$ spectra for various changes in an $(R C)$ circuit. Initial values are $R_{A}=1 \Omega \mathrm{cm}^{2}$ and $C_{A}=1 \mathrm{mF} / \mathrm{cm}^{2}$. All increases are $10 \%$ and all decreases are $9 \%$.

decreases" and " $C$ increases" in Fig. 2 are capacitive. "Resistive" is change in the resistance $R$ with a constant $C$. The $\Delta \dot{Z}$ ' spectra " $R$ increases" and " $R$ decreases" in Fig. 2 are resistive.

A number of simple models of physical changes result in a timeinvariant $\Delta \dot{Z}^{\prime}$ spectrum. For instance, a change in the exchange volume in a continuous stirred tank reactor (CSTR) model of conversion impedance ${ }^{8}$ would result in a time-invariant $\Delta \dot{Z}^{\prime}$ spectrum. Likewise, one could think of processes related to the triple-phase boundary (TPB) (such as adsorption or desorption) that would produce a time-invariant $\Delta \dot{Z}^{\prime}$ spectrum if the length of the active triple phase boundary is changed (because the double-layer capacitance is inverse proportional to the TPB length, whereas the resistance associated with the process is proportional to the TPB length).

In Fig. 2, the time-invariant $\Delta \dot{Z}^{\prime}$ spectrum only attains positive values or negative values, whereas both the capacitive and resistive $\Delta \dot{Z}^{\prime}$ spectra attain both negative and positive values. In the Appendix it is shown that this also applies to $(R Q)$ circuits and to Gerischer elements. This makes it possible to distinguish the timeinvariant $\Delta \dot{Z}^{\prime}$ spectrum from the capacitive or resistive $\Delta \dot{Z}^{\prime}$ spectrum. Note that for a time-invariant $\Delta \dot{Z}^{\prime}$ spectrum of an $(R C)$ circuit, $\Delta \dot{Z}^{\prime}(\omega)$ has its peak frequency (i.e., local maximum or minimum) at $\omega^{o}$.

\section{Results}

Figure 3 shows impedance spectra recorded on an SOFC. The upper figure shows spectra recorded with $\mathrm{O}_{2}$ diluted with $0,20,50$, or $75 \mathrm{vol} \% \mathrm{~N}_{2}$ supplied to the LSM/YSZ electrode at a rate of $20 \mathrm{~L} / \mathrm{h}$. The Ni/YSZ electrode was fed with $\mathrm{H}_{2}$ containing 50 vol \% $\mathrm{H}_{2} \mathrm{O}$ at a rate of $25 \mathrm{~L} / \mathrm{h}$. The lower figure shows spectra recorded with pure $\mathrm{O}_{2}\left(0 \mathrm{vol} \% \mathrm{~N}_{2}\right)$ supplied at a rate of $20 \mathrm{~L} / \mathrm{h}$ to the LSM/ YSZ electrode and with $\mathrm{H}_{2}$ containing 5, 20, or 50 vol $\% \mathrm{H}_{2} \mathrm{O}$ supplied at a rate of $25 \mathrm{~L} / \mathrm{h}$ to the Ni/YSZ electrode.

At first glance, the spectra in Fig. 3 show three separable arcs. In order to obtain more detailed information about the number of $z_{j} \mathrm{~s}$ that contribute to the SOFC spectra and to which of the electrodes the $z_{j}$ s belong, the spectra in Fig. 3 were used to form $\Delta \dot{Z}^{\prime}$ spectra.

Referring to the upper part of Fig. 3, an impedance spectrum was recorded with pure $\mathrm{O}_{2}$ to the LSM/YSZ electrode. Then, the gas to the LSM/YSZ electrode was changed to $\mathrm{O}_{2}$ diluted with $\mathrm{N}_{2}$ and another spectrum was recorded. Finally, the gas was reverted to pure 

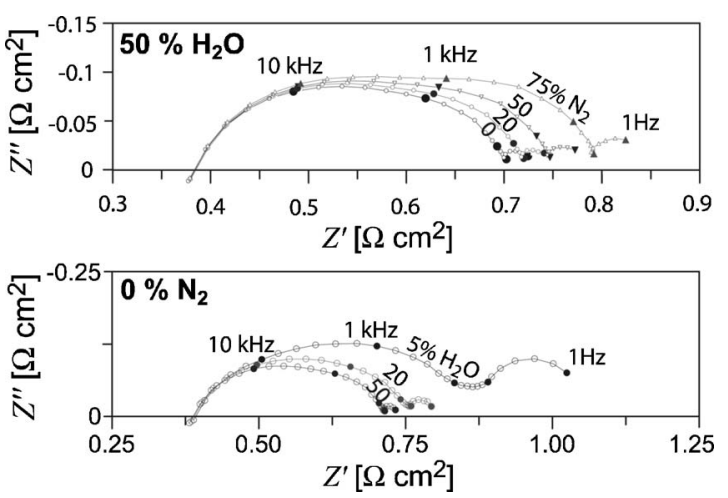

Figure 3. (Top) Impedance spectra recorded with $\mathrm{O}_{2}$ diluted in 0,20 , 50, or $75 \mathrm{vol} \% \mathrm{~N}_{2}$ fed to the LSM/YSZ electrode and $\mathrm{H}_{2}$ containing $50 \mathrm{vol} \%$ $\mathrm{H}_{2} \mathrm{O}$ to the Ni/YSZ electrode. (Bottom) Impedance spectra recorded with $\mathrm{H}_{2}$ containing 5, 20, or $50 \mathrm{vol} \% \mathrm{H}_{2} \mathrm{O}$ fed to the $\mathrm{Ni} / \mathrm{SZ}$ electrode and pure $\mathrm{O}_{2}$ to the LSM/YSZ electrode.

$\mathrm{O}_{2}$ and a third spectrum was recorded. A $\Delta \dot{Z}^{\prime}$ spectrum was made using the first and second impedance spectrum as described in the previous section. Another $\Delta \dot{Z}^{\prime}$ spectrum was made using the second and third spectrum. By subtracting the second $\Delta \dot{Z}^{\prime}$ spectrum from the first and dividing by two, an average $\Delta \dot{Z}^{\prime}$ spectrum was made.

The average $\Delta \dot{Z}^{\prime}$ spectrum is better than the single-shift $\Delta \dot{Z}^{\prime}$ spectrum in the sense that the signal-to-noise ratio is increased by a factor of 2. Furthermore, time-dependent passivation or activation of the electrodes that is unaffected by the gas change is suppressed by an order of magnitude.

In order to assure that a drift or extended relaxation due to the gas change does not influence the impedance spectra, it should be checked that the spectra obey the Kramers-Kronig relations. Because electrical circuit models satisfy the Kramers-Kronig relations, a system can be judged to be stationary if a satisfactory fit to an equivalent circuit model can be obtained. ${ }^{14,15}$

All the impedance spectra are tested by modeling the spectra with an equivalent circuit of the Voigt type, $L R(R Q) W_{0}(R Q)(R Q)$ $\times(R Q) . L$ is an inductance in series with $R$, an ohmic resistance. The brackets indicate that $(R Q)$ is a parallel circuit consisting of a resistance and a constant phase element. $W_{0}$ is a finite-length Warburg element with a transmissive boundary condition. ${ }^{16}$ The error between fit and measurement relative to $|Z|$ was less than $1 \%$ for both the real and imaginary part in all spectra at all frequencies. Hence, drift or extended relaxation is known to be limited.

The noise in the resulting average $\Delta \dot{Z}^{\prime}$ spectrum was further reduced by using a moving average of three points, plotting each point, $\Delta \dot{Z}^{\prime}\left(\omega_{n}\right)$, as an average of the values obtained at $\omega_{n-1}, \omega_{n}$, and $\omega_{n+1}$. The result is shown in Fig. 4. A noise-reduced (or moving

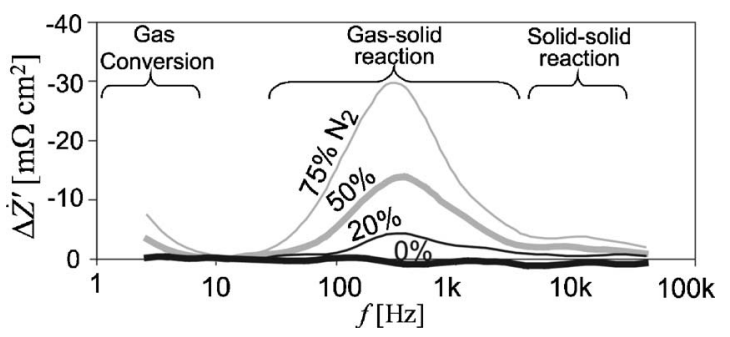

Figure 4. $\Delta \dot{Z}^{\prime}$ spectra recorded on an SOFC with a gas shift to the LSM/ YSZ electrode from pure $\mathrm{O}_{2}$ to $\mathrm{O}_{2}$ diluted in $0,20,50$, or $75 \mathrm{vol} \% \mathrm{~N}_{2}$. The bold line $(0 \%)$ is a background noise measurement. All spectra are recorded with $\mathrm{H}_{2}$ containing 50 vol $\% \mathrm{H}_{2} \mathrm{O}$ to the $\mathrm{Ni} / \mathrm{YSZ}$ electrode.

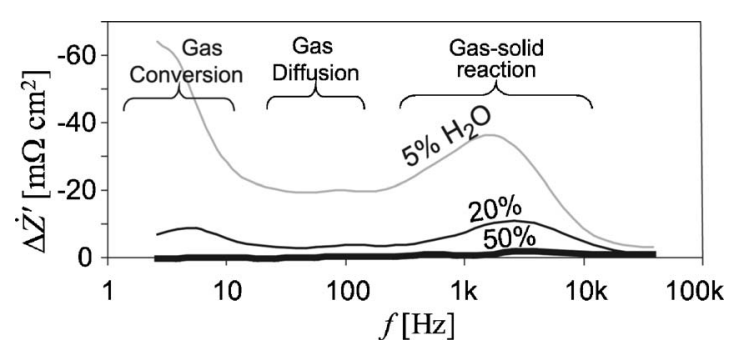

Figure 5. $\Delta \dot{Z}^{\prime}$ spectra recorded on an $\mathrm{SOFC}$ with a gas shift to the Ni/YSZ electrode from $\mathrm{H}_{2}$ containing 50 vol $\% \mathrm{H}_{2} \mathrm{O}$ to $\mathrm{H}_{2}$ containing 5, 20, or $50 \mathrm{vol} \% \mathrm{H}_{2} \mathrm{O}$. The bold line $(50 \%)$ is a background noise measurement. All spectra are recorded with pure $\mathrm{O}_{2}$ to the LSM/YSZ electrode.

average of three points) $\Delta \dot{Z}^{\prime}$ spectrum from $0 \mathrm{vol} \% \mathrm{~N}_{2}$ to $0 \mathrm{vol} \%$ $\mathrm{N}_{2}$ was made to measure the uncertainty or background noise of the measurement technique and is plotted as the bold black line.

The number of measurement points used in this work is six points per frequency decade. The synthetic $\Delta \dot{Z}^{\prime}$ spectra (shown in the Appendix) indicate that the peaks, which we probably would find, are stretched over a frequency decade or even more. For this reason, it is unlikely to find any additional features in the $\Delta \dot{Z}^{\prime}$ spectra by increasing the number of frequency points per decade.

If the number of points were increased, the time used to produce the impedance spectra would increase. This may increase possible errors due to drift, electrode relaxation, or unstable measurement conditions. Increasing the number of ac cycles at each measurement point also decreases the noise provided that no changes over time take place. Thus, the optimal number of points per frequency decade as well as the optimal number of ac cycles per point has to be assessed in each case.

The $\Delta \dot{Z}^{\prime}$ spectra in Fig. 4 reveal three separable peaks, indicating that at least three different types of processes occur at the LSM/YSZ electrode and contribute to the impedance spectra. The summit frequency, $f^{o}=\omega^{o} / 2 \pi$, of the LSM/YSZ electrode arcs in pure $\mathrm{O}_{2}$ can be approximated by drawing a straight line through the peaks of the $\Delta \dot{Z}^{\prime}$ spectrum to the $x$ axis. The frequency at the intercept with the $x$ axis is the approximate summit frequency for the LSM/YSZ electrode arcs in pure $\mathrm{O}_{2}$. These frequencies are $\{<10 \mathrm{~Hz}$; $\sim 300 \mathrm{~Hz} ; \sim 10 \mathrm{kHz}\}$. The processes behind the three observed peaks are elaborated on in the next section.

Referring to the lower part of Fig. 3, an impedance spectrum was recorded with $\mathrm{H}_{2}$ containing 50 vol \% $\mathrm{H}_{2} \mathrm{O}$ to the $\mathrm{Ni} / \mathrm{YSZ}$ electrode. The steam concentration was subsequently changed to 5 or $20 \mathrm{vol} \%$ $\mathrm{H}_{2} \mathrm{O}$ and another impedance spectrum was recorded. Finally, the steam concentration was reverted back to $50 \mathrm{vol} \% \mathrm{H}_{2} \mathrm{O}$ and a third spectrum was recorded. The spectra were used to produce average noise-reduced $\Delta \dot{Z}^{\prime}$ spectra like the ones shown in Fig. 4. The result is shown in Fig. 5. A noise-reduced $\Delta \dot{Z}^{\prime}$ spectrum from 50 vol \% $\mathrm{H}_{2} \mathrm{O}$ to 50 vol $\% \mathrm{H}_{2} \mathrm{O}$ was made to determine the background noise of the measurement technique and is plotted as the bold black line.

The $\Delta \dot{Z}^{\prime}$ spectra in Fig. 5 reveals three separable peaks, indicating that at least three different types of processes occur at the $\mathrm{Ni} /$ YSZ electrode and contribute to the impedance spectra. Again, the summit frequency can be found by drawing a straight line through the $\Delta \dot{Z}^{\prime}$ spectra peaks to the $x$ axis. The frequency at the intercept with the $x$ axis is the approximate summit frequency for the electrode arcs in $\mathrm{H}_{2}$ containing 50 vol $\% \mathrm{H}_{2} \mathrm{O}$. The frequencies are $\{<10 \mathrm{~Hz} ; \sim 80 \mathrm{~Hz} ; \sim 2 \mathrm{kHz}\}$.

The gas-diffusion peak is not clearly visible in Fig. 5. To enhance the visibility of the gas-diffusion process, a $\mathrm{H}-\mathrm{D}$ isotope experiment was made. First, a $\mathrm{H}_{2}$ impedance spectrum $\left(\mathrm{H}_{2}\right.$ containing $20 \% \mathrm{H}_{2} \mathrm{O}$ at a rate of $10 \mathrm{~L} / \mathrm{h}$ ) was recorded and subsequently a $\mathrm{D}_{2}$ 


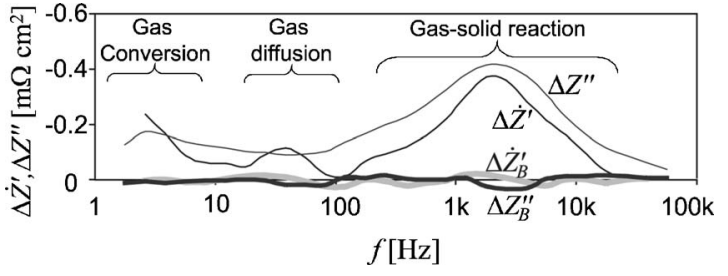

Figure 6. $\Delta \dot{Z}^{\prime}$ and $\Delta Z^{\prime \prime}$ for a gas shift from $\mathrm{H}_{2}$ containing 20 vol $\% \mathrm{H}_{2} \mathrm{O}$ to $\mathrm{D}_{2}$ containing $20 \mathrm{vol} \% \mathrm{D}_{2} \mathrm{O} . \Delta \dot{Z}_{\mathrm{B}}^{\prime}$ and $\Delta Z_{\mathrm{B}}^{\prime \prime}$ are background-noise measures. Note that $\Delta \dot{Z}^{\prime}$ reveals three peaks while $\Delta Z^{\prime \prime}$ only reveals two and the fluctuations of $\Delta \dot{Z}_{\mathrm{B}}^{\prime}$ and $\Delta Z_{\mathrm{B}}^{\prime \prime}$ are of similar magnitude.

spectrum $\left(\mathrm{D}_{2}\right.$ containing $20 \% \mathrm{D}_{2} \mathrm{O}$ at a rate of $\left.10 \mathrm{~L} / \mathrm{h}\right)$ was recorded. Then, the gas was switched back to $\mathrm{H}_{2}$ containing $20 \% \mathrm{H}_{2} \mathrm{O}$ supplied at a rate of $10 \mathrm{~L} / \mathrm{h}$ and another $\mathrm{H}_{2}$ spectrum was recorded. The LSM/YSZ electrode was fed with $20 \mathrm{~L} / \mathrm{h} \mathrm{O}_{2}$ during the entire recording sequence. An average, noise-reduced $\Delta \dot{Z}^{\prime}$ spectrum for these conditions is shown in Fig. 6. $\Delta \dot{Z}_{\mathrm{B}}^{\prime}$ is the background noise of the $\Delta \dot{Z}^{\prime}$ spectrum and is a noise-reduced $\Delta \dot{Z}^{\prime}$ spectrum produced with the two $\mathrm{H}_{2}$ spectra.

It might be argued that $\Delta Z^{\prime \prime}$ is an equally good indicator of the summit frequency of a given process. Hence, for comparison, the average noise-reduced $\Delta Z^{\prime \prime}$ is also plotted in Fig. 6. $\Delta Z_{\mathrm{B}}^{\prime \prime}$ is the noise-reduced uncertainty measure of $\Delta Z^{\prime \prime}$ using the first and second $\mathrm{H}_{2}$ spectra. The three observed peaks in the $\Delta \dot{Z}^{\prime}$ spectrum are discussed in the next section. Note that the gas-diffusion peak is only observed with $\Delta \dot{Z}^{\prime}$ and that the fluctuations of $\Delta \dot{Z}_{\mathrm{B}}^{\prime}$ and $\Delta Z_{\mathrm{B}}^{\prime \prime}$ are of similar magnitude.

\section{Discussion}

The $\Delta \dot{Z}^{\prime}$ spectra in Fig. 4 reveal three identifiable peaks. Using a three-electrode setup, Jorgensen and Mogensen have reported that up to five different processes may contribute to the LSM/YSZ electrode. ${ }^{5}$ Barfod et al. investigated a symmetrical cell with LSM/ YSZ electrodes on either side of the YSZ electrode. ${ }^{6}$ Three separable arcs were found in the impedance spectra with summit frequencies in good agreement with the low-, medium-, and highfrequency peaks in Fig. 4. The arc with a summit frequency of $\sim 10 \mathrm{kHz}$ was ascribed to oxygen-intermediate transport in the LSM/YSZ structure near the electrode-electrolyte interface, the arc with a summit frequency of $\sim 300 \mathrm{~Hz}$ to dissociative adsorbtion/ desorbtion of $\mathrm{O}_{2}$ and transfer of species across the TPB, and the low-frequency arc $\left(f_{\mathrm{s}}<10 \mathrm{~Hz}\right)$ to gas diffusion. ${ }^{5,6}$

As the LSM/YSZ electrode is relatively thin on commercial cells $(\sim 20 \mu \mathrm{m})$, gas-diffusion limitation is expected to be limited. ${ }^{6}$ It is instead suggested that the observed low-frequency peak is due to gas conversion in the gas-distributor plate on top of the electrode. When pure $\mathrm{O}_{2}$ is fed to the LSM/YSZ electrode the gas-conversion arc disappears because the $\mathrm{O}_{2}$ partial pressure is constant and equal to the total pressure.

Three separable arcs have previously been observed in impedance spectra recorded on the $\mathrm{Ni} / \mathrm{YSZ}$ electrode in a three-electrode setup. ${ }^{7-10}$ The summit frequencies were reported as $0.1-10 \mathrm{~Hz}$ for the low-frequency arc, $10 \mathrm{~Hz}-1 \mathrm{kHz}$ for the medium-frequency arc, and $1-50 \mathrm{kHz}$ for the high-frequency arc. The low-frequency arc was attributed to gas conversion ${ }^{8}$ and the medium-frequency arc was attributed to gas diffusion. ${ }^{9}$ The high-frequency arc has been found in a number of Ni/YSZ electrode setups. ${ }^{10} \mathrm{~A}$ gas-solid (desorption, absorption, dissociation) or solid-solid (surface diffusion, ion transfer across the double layer) reaction has been proposed for this electrode arc. ${ }^{7,10}$ The three observed arcs are in good correspon- dence with the gas conversion, the gas diffusion, and the gas-solid reaction ?? ${ }^{\text {? }}$ peak observed in the $\Delta \dot{Z}^{\prime}$ spectra in Fig. 5 and 6 .

In Fig. 5 the gas-diffusion peak is small compared to the gasconversion and the gas-solid reaction peaks. In Fig. 6, the isotope exchange should not affect the gas-conversion arc. This explains why in Fig. 6 the gas-conversion peak is smaller, relative to the gas-diffusion peak. The reason why the gas-conversion peak is observed is possibly due to some small calibration error in the feed gas-flow rate when shifting from $\mathrm{H}_{2}$ to $\mathrm{D}_{2}$. Alternatively, it may be that the equalization of the partial pressure of reactants in the gas volume to some degree involves gas diffusion. ${ }^{8}$

The $\Delta \dot{Z}^{\prime}$ gas-solid peak in Fig. 6 seems to be well separated from the other peaks (no overlap). Hence, the peak may represent a time-invariant shift of the involved process. If the process that is responsible for the peak is adsorption or desorption of $\mathrm{H}_{2} \mathrm{O}$ or $\mathrm{H}_{2}$, a change in the active surface area would result in a time-invariant peak. From classical statistical mechanics it is predicted that the conductivity of $\mathrm{D}^{+}$in a solid is $1 / \sqrt{2}$ that of $\mathrm{H}^{+}$because the "attempt frequency" scales with $1 / \sqrt{m}$, where $m$ is the mass of the isotope. ${ }^{17}$ At $500 \mathrm{~K}$ the ratio between the $\mathrm{H}^{+}$and $\mathrm{D}^{+}$conductivity, $\sigma_{\mathrm{H}} / \sigma_{\mathrm{D}}$, in a number of proton conductors has been observed to vary from $\sim 1.5$ to $\sim 3.5 .{ }^{18} \mathrm{H}_{2}$ and $\mathrm{D}_{2}$ diffusion in single-crystal $\mathrm{Ni}$ between 400 and $950^{\circ} \mathrm{C}$ has been investigated by Katz et al. ${ }^{19}$ The diffusion coefficient was found to decrease about $20 \%$ at $750^{\circ} \mathrm{C}$ when shifting from $\mathrm{H}_{2}$ to $\mathrm{D}_{2}$. Hence, a substitution of $\mathrm{H}_{2}$ with $\mathrm{D}_{2}$ is likely to cause a decrease in the active surface area (the extension of the TPB) of the electrode, which would cause the observed gas-solid $\Delta \dot{Z}^{\prime}$ spectrum peak for the Ni/YSZ electrode reaction.

As discussed in the Appendix, the $\Delta \dot{Z}^{\prime}$ spectrum provides a better resolution of the individual process contributions than a $\Delta Z^{\prime \prime}$ spectrum because it yields sharper and better-defined peaks around $\omega_{\mathrm{i}}^{o}$, the characteristic frequency for the impedance element $z_{\mathrm{i}}$. This is confirmed experimentally in Fig. 6, where the $\Delta \dot{Z}^{\prime}$ spectrum reveals the gas-diffusion peak in contrast to the $\Delta Z^{\prime \prime}$ spectrum.

The presented method to analyze differences in impedance spectra by variation of test conditions may be applied to other electrochemical devices, because it enables a selective study of process contributions to the impedance.

\section{Conclusion}

An SOFC was investigated based on differences in impedance spectra due to a change of operating parameters. Plotting the difference in the derivative with respect to $\ln (f)$ of the real part of the impedance is shown to be helpful in separating processes that overlap in impedance spectra. The produced $\Delta \dot{Z}^{\prime}$ spectra revealed three identifiable peaks at the LSM/YSZ electrode and three at the $\mathrm{Ni}$ / YSZ electrode. Each peak in the $\Delta \dot{Z}^{\prime}$ spectra corresponds to a change in a process that contributes to the impedance spectra.

The three $\Delta \dot{Z}^{\prime}$ spectrum peaks observed at the LSM/YSZ electrode had peak frequencies around $\{10 \mathrm{~Hz}, \sim 300 \mathrm{~Hz}, \sim 10 \mathrm{kHz}\}$ at $750^{\circ} \mathrm{C}$. This is in good agreement with previous findings in a three-electrode setup and a symmetrical-cell setup. ${ }^{5,6}$

The Ni/YSZ electrode has previously been investigated in a three-electrode setup where a gas-conversion $\operatorname{arc}^{7,8}(0.1-10 \mathrm{~Hz})$, a gas-diffusion $\operatorname{arc}^{9}(10 \mathrm{~Hz}-1 \mathrm{kHz})$, and a gas-solid or solid-solid $\operatorname{arc}^{9,10}(1-10 \mathrm{kHz})$ were found. This is in good correspondence with the observed $\Delta \dot{Z}^{\prime}$ spectrum peaks, which had peak frequencies at $\{<10 \mathrm{~Hz} ; \sim 80 \mathrm{~Hz} ; \sim 2 \mathrm{kHz}\}$.

Evidence for gas diffusion at the Ni/YSZ electrode was revealed in an isotope experiment where hydrogen was exchanged with deuterium. The produced $\Delta \dot{Z}^{\prime}$ spectrum reveals a peak around $80 \mathrm{~Hz}$.

\footnotetext{
${ }^{c}$ For simplicity, the high-frequency peak is referred to as a gas-solid reaction.
} 
No evidence for diffusion was found in a $\Delta Z^{\prime \prime}$ spectrum. The enhanced resolution of processes in a $\Delta \dot{Z}^{\prime}$ spectrum compared with a $\Delta Z^{\prime \prime}$ spectrum is discussed in the appendix.

\section{Acknowledgments}

The authors thank the Fuel Cell and Solid State Department at Risø National Laboratory, Technical University of Denmark (DK), the Danish Energy Authority via the SERC project, contract no. 2104-06-0011, and the European Commission via the $\mathrm{Hi}_{2} \mathrm{H}_{2}$ project, contract no. FP6-503765 for interest and financial support. article.

Ris $\phi$ National Laboratory assisted in meeting the publication costs of this

\section{Appendix}

Below we calculate $Z$ and $\dot{Z}$ for an $(R C)$ circuit, an $(R Q)$ circuit, and a Gerischer element. After this, some discussion on $\Delta \dot{Z}^{\prime}$ follows, and finally an example of a $\Delta \dot{Z}^{\prime}$ spectrum is given.

\section{(RC) circuit}

The impedance, $Z(\omega)$, for an $(R C)$ circuit where $\omega=2 \pi f$ is the angular frequency is given as

$$
Z(\omega)=\frac{R}{1+j \omega R C}=\frac{R}{1+j \omega / \omega^{\circ}}=\frac{R}{1+x}
$$

where $\omega^{o}=1 / R C$ and $x=j \omega / \omega^{o}$. We can now find the derivative with respect to $\ln (\omega)$ as

$$
\dot{Z}=\frac{\partial Z(\omega)}{\partial \ln (\omega)}=\frac{\partial Z}{\partial x} \frac{\partial x}{\partial \omega} \frac{\partial \omega}{\partial \ln (\omega)}=-\frac{R}{(1+x)^{2}} \frac{j}{\omega^{\omega}} \omega=-R \frac{x}{(1+x)^{2}}
$$

\section{(RQ) circuit}

The impedance, $Z(\omega)$, of an $(R Q)$ circuit, where $Q$ is a constant-phase element with the impedance $Z_{Q}(\omega)=1 / Y_{0}(j \omega)^{n}$, is given as

$$
Z(\omega)=\frac{R}{1+R Y_{0}(j \omega)^{n}}=\frac{R}{1+\left(j \omega / \omega^{o}\right)^{n}}=\frac{R}{1+y}
$$

where $\omega^{o}=\left(R Y_{0}\right)^{-1 / n}$ and $y=\left(j \omega / \omega^{o}\right)^{n}$.

The derivative with respect to $\ln (\omega)$ can be found as

$$
\dot{Z}=\frac{\partial Z(\omega)}{\partial \ln (\omega)}=\frac{\partial Z}{\partial y} \frac{\partial y}{\partial \omega} \frac{\partial \omega}{\partial \ln (\omega)}=-\frac{R}{(1+y)^{2}}\left(\frac{j}{\omega^{o}}\right)^{n} n \omega^{n-1} \quad \omega=-n R \frac{y}{(1+y)^{2}}
$$

Note that when $n=1$, Eq. A-3 reduces to A-1 and A-4 reduces to A-2.

\section{Gerischer element}

The impedance for a Gerischer element may be written as

$$
Z(\omega)=\frac{R}{\left(1+\omega / \omega^{o}\right)^{1 / 2}}=\frac{R}{(1+x)^{1 / 2}}
$$

and the derivative with respect to $\ln (\omega)$ is found as

$$
\dot{Z}=\frac{\partial Z(\omega)}{\partial \ln (\omega)}=\frac{\partial Z}{\partial x} \frac{\partial x}{\partial \omega} \frac{\partial \omega}{\partial \ln (\omega)}=-\frac{R x}{2(1+x)^{3 / 2}}
$$

For the $(R C)$ element, separating into real and imaginary parts yields

$$
Z=\frac{R}{1+\left(\omega / \omega^{o}\right)^{2}}-j \frac{R \omega / \omega^{o}}{1+\left(\omega / \omega^{o}\right)^{2}}
$$

and

$$
\dot{Z}=-\frac{2 R\left(\omega / \omega^{o}\right)^{2}}{\left[1+\left(\omega / \omega^{o}\right)^{2}\right]^{2}}+j \frac{R\left(\omega / \omega^{o}\right)\left[1-\left(\omega / \omega^{o}\right)^{2}\right]}{\left[1+\left(\omega / \omega^{o}\right)^{2}\right]^{2}}
$$

From Eq. A-7 and A-8 it is seen that

$$
\dot{Z}^{\prime}=-\frac{2}{R}\left(Z^{\prime \prime}\right)^{2}
$$

where $\dot{Z}^{\prime}$ is the real part of $Z^{\prime}$ and $Z^{\prime \prime}$ is the imaginary part of $Z$. This explains why $\dot{Z}^{\prime}$ produces a sharper and more well-defined peak than $Z^{\prime \prime}$. From Eq. A-9 it is also seen that $\dot{Z}^{\prime}$ and $Z^{\prime \prime}$ has a maximum (or minimum) at the same frequency. Taking the derivative of Eq. A-7 with respect to $\omega$, this frequency can be shown to be $\omega^{\circ}$. Figure A-1 shows a plot of $\dot{Z}^{\prime}$ and $Z^{\prime \prime}$ for an $(R Q)_{1}$ and the Gerischer ${ }_{2}$ and $(R C)_{3}$ elements, given the values in Table A-I, condition A.

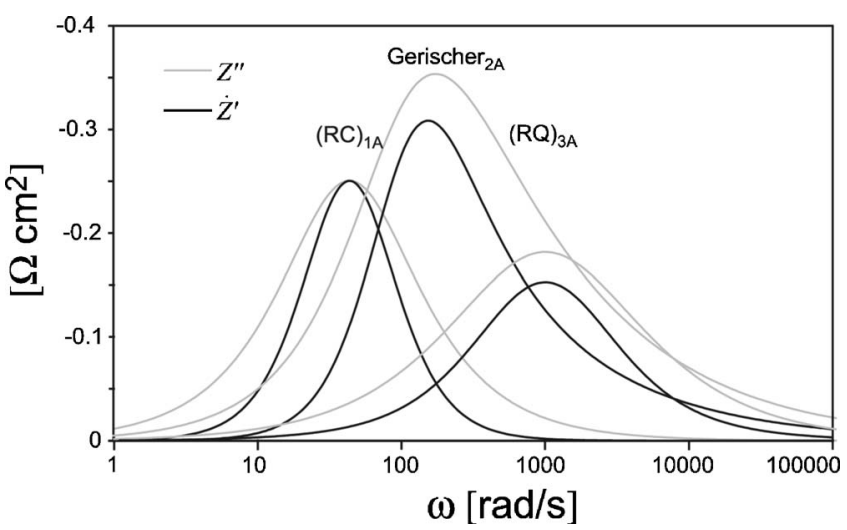

Figure A-1. $\dot{Z}^{\prime}$ and $Z^{\prime \prime}$ for $(R Q)_{1}$, a Gerischer 2 , and an $(R C)_{3}$, with the values specified in Table I, condition A. Note that $\dot{Z}^{\prime}$ produces sharper and more well-defined peaks than $Z^{\prime \prime}$.

In general, an impedance spectrum is a sum of responses from several processes with different characteristic time constants. For simplicity, let us examine the response arising from two $(R C) \mathrm{s}$ in series, which we shall denote $(R C)_{1}$ and $(R C)_{2}$.

For such a circuit we can find

$$
\dot{Z}^{\prime}=-\frac{2 R\left(\omega / \omega_{1}^{o}\right)^{2}}{\left[1+\left(\omega / \omega_{1}^{o}\right)^{2}\right]^{2}}-\frac{2 R\left(\omega / \omega_{2}^{o}\right)^{2}}{\left[1+\left(\omega / \omega_{2}^{o}\right)^{2}\right]^{2}}
$$

where $\omega_{1}^{o}=1 / R C$ for $(R C)_{1}$ and $\omega_{2}^{o}=1 / R C$ for $(R C)_{2}$. If $\omega_{1}^{o} \neq \omega_{2}^{o}$, a $\dot{Z}^{\prime}$ vs $\log (\omega)$ graph produces two overlapping peaks. We can also find

$$
Z^{\prime \prime}=-\left[\frac{R \omega / \omega_{1}^{o}}{1+\left(\omega / \omega_{1}^{o}\right)^{2}}+\frac{R \omega / \omega_{2}^{o}}{1+\left(\omega / \omega_{2}^{o}\right)^{2}}\right]
$$

which also gives two peaks in a Bode plot, but the peaks are not as well separated as for $\dot{Z}^{\prime}$. Taking the square of Eq. A-11 does not result in well-separated peaks in a Bode plot due to the formation of a cross term of the form

$$
2 \frac{\omega / \omega_{1}^{o}}{1+\left(\omega / \omega_{1}^{o}\right)^{2}} \cdot \frac{\omega / \omega_{2}^{o}}{1+\left(\omega / \omega_{2}^{o}\right)^{2}}
$$

\begin{tabular}{|c|c|c|c|}
\hline Circuit element & Parameter & Condition A & Condition B \\
\hline$(R Q)_{1}$ & $R_{1}\left(\Omega \mathrm{cm}^{2}\right)$ & 0.5 & 0.53 \\
\hline element & $\omega_{1}^{o}(\mathrm{rad} / \mathrm{s})$ & 1000 & 1000 \\
\hline & $n_{1}$ & 0.8 & 0.8 \\
\hline Gerischer $_{2}$ & $R_{2}\left(\Omega \mathrm{cm}^{2}\right)$ & 1 & 1.1 \\
\hline element & $\omega_{2}^{o}(\mathrm{rad} / \mathrm{s})$ & 100 & 90.9 \\
\hline$(R C)_{3}$ & $R_{3}\left(\Omega \mathrm{cm}^{2}\right)$ & 0.5 & 0.5 \\
\hline element & $\omega_{3}^{o}(\mathrm{rad} / \mathrm{s})$ & 43 & 40 \\
\hline
\end{tabular}

Now assume that an operation parameter $\Psi$ is changed from condition A to B such that $(R C)_{1}$ is affected but $(R C)_{2}$ remains constant. It then follows that $\Delta \dot{Z}^{\prime}$ is given as

$$
\begin{aligned}
\Delta \dot{Z}^{\prime} & =\left\{\frac{2 R\left(\omega / \omega_{1}^{o}\right)^{2}}{\left[1+\left(\omega / \omega_{1}^{o}\right)^{2}\right]^{2}}+\frac{2 R\left(\omega / \omega_{2}^{o}\right)^{2}}{\left[1+\left(\omega / \omega_{2}^{o}\right)^{2}\right]^{2}}\right\}_{\mathrm{A}}-[\ldots]_{\mathrm{B}} \\
& =\left\{\frac{2 R\left(\omega / \omega_{1}^{o}\right)^{2}}{\left[1+\left(\omega / \omega_{1}^{o}\right)^{2}\right]^{2}}\right]_{\mathrm{A}}-\left[\frac{2 R\left(\omega / \omega_{1}^{o}\right)^{2}}{\left[1+\left(\omega / \omega_{1}^{o}\right)^{2}\right]^{2}}\right\}_{\mathrm{B}}
\end{aligned}
$$

If $\left.\left.\omega_{1}^{o}\right|_{\mathrm{A}} \simeq \omega_{1}^{o}\right|_{\mathrm{B}}$, Eq. A-13 can be further simplified to give

$$
\Delta \dot{Z}^{\prime} \simeq \frac{2\left(\left.R\right|_{\mathrm{A}}-\left.R\right|_{\mathrm{B}}\right)\left(\omega / \omega_{1}^{o}\right)^{2}}{\left[1+\left(\omega / \omega_{1}^{o}\right)^{2}\right]^{2}}
$$

Comparing the real part of Eq. A-8 and A-14, it is seen that $\Delta \dot{Z}^{\prime}$ produces a peak with similar shape to the $\Delta \dot{Z}^{\prime}$ peak shown in Fig. A-1 with center at $\omega_{1}^{o}$, but rescaled with a factor $\left(\left.R\right|_{\mathrm{A}}-\left.R\right|_{\mathrm{B}}\right) /\left.R\right|_{\mathrm{A}}$. Given the same assumptions as for the calculation of $\Delta \dot{Z}^{\prime}$, $\Delta Z^{\prime \prime}$ can be found as 


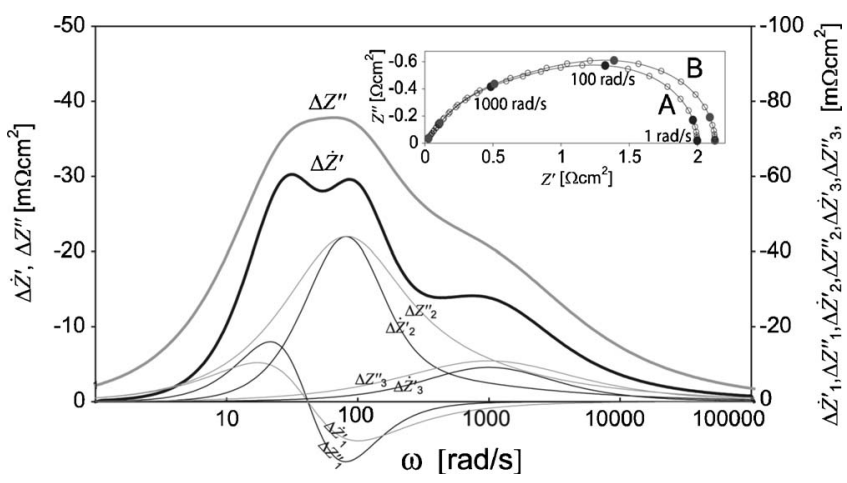

Figure A-2. $\Delta \dot{Z}^{\prime}$ and $\Delta Z^{\prime \prime}$ for $(R Q)_{1}$, Gerischer ${ }_{2}$, and $(R C)_{3}$ in series, undergoing a change in $\Psi$ from condition A to B as specified in Table I. The thin lines are $\Delta \dot{Z}^{\prime}$ and $\Delta Z^{\prime \prime}$ for the individual elements. The inset is a plot of the impedance of $(R Q)_{1}$, Gerischer ${ }_{2}$, and $(R C)_{3}$ in series at condition $\mathrm{A}$ and B.

$$
\Delta Z^{\prime \prime} \simeq \frac{\left(\left.R\right|_{\mathrm{A}}-\left.R\right|_{\mathrm{B}}\right) \omega / \omega_{1}^{o}}{1+\left(\omega / \omega_{1}^{o}\right)^{2}}
$$

which produces a peak with a similar shape to the $Z^{\prime \prime}$ peak shown in Fig. A-1 with center at $\omega_{1}^{o}$, but rescaled with a factor $\left(\left.R\right|_{\mathrm{A}}-\left.R\right|_{\mathrm{B}}\right) /\left.R\right|_{\mathrm{A}}$. Looking at Eq. A-3 through A- 6 , it is clear that if $\omega^{o}$ is preserved, the peak shape is preserved. From Fig. A-1 it is then seen that a time-invariant (i.e., $\omega^{o}$-preserving) $\Delta \dot{Z}^{\prime}$ spectrum (from a single impedance element) only attains positive or negative values (and not both positive and negative values.)

Figure A-2 presents $\Delta \dot{Z}^{\prime}$ and $\Delta Z^{\prime \prime}$ for an $(R Q)$, a Gerischer, and an $(R C)$ element in series, undergoing a change in $\Psi$ from condition A to B. The elements are referred to as
$(R Q)_{1}$, Gerischer 2 , and $(R C)_{3}$, and the parameter values for the elements are specified in Table A-I. $(R Q)_{1}$ undergoes a time-invariant change, Gerischer $_{2}$ undergoes a resistive change, and $(R C)_{3}$ undergoes a capacitive change. Note that the three peaks are better resolved in the $\Delta \dot{Z}^{\prime}$ spectrum than in the $\Delta Z^{\prime \prime}$ spectrum.

\section{References}

1. H. Schichlein, A. C. Muller, M. Voigts, A. Krugel, and E. Ivers-Tiffee, J. Appl. Electrochem., 32, 875 (2002).

2. D. Vladikova, G. Raikova, Z. Stoynov, H. Takenouti, J. Kilner, and S. Skinner, Solid State Ionics, 176, 2005 (2005).

3. D. Vladikova, P. Zoltowski, E. Makowska, and Z. Stoynov, Electrochim. Acta, 47, 2943 (2002).

4. K. Darowicki, Electrochim. Acta, 43, 2281 (1998).

5. M. J. Jorgensen and M. Mogensen, J. Electrochem. Soc., 148, A433 (2001).

6. R. Barfod, A. Hagen, S. Ramousse, P. V. Hendriksen, and M. Mogensen, Fuel Cells, 6, 141 (2006).

7. S. Primdahl and M. Mogensen, J. Electrochem. Soc., 144, 3409 (1997)

8. S. Primdahl and M. Mogensen, J. Electrochem. Soc., 145, 2431 (1998).

9. S. Primdahl and M. Mogensen, J. Electrochem. Soc., 146, 2827 (1999).

10. S. Primdahl, Ph.D. Thesis, Risø National Laboratory, Denmark (1999).

11. K. K. Hansen, P. H. Larsen, Y. L. Liu, B. Kindl, and M. Mogensen, in Proceedings of the 5th European Solid Oxide Fuel Cell Forum, European Fuel Cell Forum, Oberrohrdorf, Switzerland (2002).

12. N. Christiansen, S. Kristensen, H. Holm-Larsen, P. H. Larsen, M. Mogensen, P. V. Hendriksen, and S. Linderoth, in Proceedings of the 5th European Solid Oxide Fuel Cell Forum, European Fuel Cell Forum, Oberrohrdorf, Switzerland (2002).

13. M. Mogensen, P. V. Hendriksen, and K. K. Hansen, in Proceedings of the 5th European Solid Oxide Fuel Cell Forum, European Fuel Cell Forum, Oberrohrdorf, Switzerland (2002).

14. P. Agarwal, M. E. Orazem, and L. H. Garcia Rubio, J. Electrochem. Soc., 139 1917 (1992).

15. J. R. Macdonald, in Impedance Spectroscopy, 2nd ed., E. Barsoukov and J. R. Macdonald, Editors, p., 195, Wiley Interscience, Hoboken, NJ (2005).

16. J. R. Macdonald, in Impedance Spectroscopy, 2nd ed., E. Barsoukov and J. R. Macdonald, Editors, p. 58, Wiley Interscience, Hoboken, NJ (2005).

17. G. H. Vineyard, J. Phys. Chem. Solids, 1-2, 121 (1957).

18. A. S. Nowick and A. V. Vaysleyb, Solid State Ionics, 97, 17 (1997)

19. L. Katz, M. Guinan, and R. J. Borg, Phys. Rev. B, 4, 330 (1971). 